\title{
Wait or Intervene: Dentigerous Cyst Associated with Permanent Mandibular Canine
}

\author{
Amani A. Al Tuwirqi ${ }^{1}$, MPhil, DClinDent (Pediatric Dentistry) and \\ Nabil O. Khzam², DClinDent (Perio), MRACDS \\ 'Department of Dentistry, Division of Pediatric Dentistry, King Abdulaziz University \\ Jeddah, Saudi Arabia \\ ${ }^{2}$ Private Practice, Perth, 6154 Western Australia, Australia
}

\section{Correspondence}

Dr. Amani A. Al Tuwirqi

P.O. Box 80209

Jeddah 21589, Saudi Arabia

e.M: aaltuwirqi@kau.edu.sa

Submission: 01 Dec 2017

Accepted: $\quad 10$ Dec 2017

\section{Citation}

Al Tuwirqi AA, Khzam NO. Wait or intervene: dentigerous cyst associated with permanent Mandibular Canine. JKAU Med Sci 2018; 25 (1): 31-38. DOI: 10.4197/Med. 25.1.5

\begin{abstract}
Dentigerous cysts are developmental odontogenic jaw cysts. Dentigerous cysts require early detection and prompt treatment ranging from marsupialization to complete enucleation. Few of these cysts have been reported in children younger than 12 years of age. The purpose of this case report was to describe the case of an 11-yearold boy with a dentigerous cyst associated with unerupted right mandibular canine. The clinical, radiographic and histopathologic features are discussed. This case report also describes the diagnosis of a mandibular dentigerous cyst using cone beam computed tomography, successful use of conservative enucleation and explains the need for such a radical treatment approach.
\end{abstract}

\section{Keywords}

Dentigerous cyst; Odontogenic; Permanent canine; Cone beam computed tomography

\section{Introduction}

$D$ entigerous cysts (DCs) are the most common developmental odontogenic cyst. Only radicular cysts are more common than DCs in the maxillofacial region $^{[1]}$. Dentigerous cysts also known as follicular cysts originate from reduced enamel epithelium (REE). It is thought to be caused by the accumulation of fluids between the REE and the external enamel surface of the formed tooth ${ }^{[2]}$. Theses cysts are the second most common odontogenic cysts after the radicular cysts. Patients with DC have no painful symptoms unless it becomes secondarily infected, this explains the fact that these lesions are often detected only during routine radiographic imaging to investigate a failure of tooth eruption, a missing tooth or malalignment ${ }^{[3]}$.
Most DC are solitary ${ }^{[4]}$. Bilateral and multiple cysts are usually found in association with a number of syndromes including cleidocranial dysplasia, Maroteaux-Lamy syndrome and in mucopolysaccharidosi ${ }^{[5]}$. Dentigerous cysts involve impacted, unerupted, permanent teeth, supernumerary teeth, and odontomas, and rarely may involve primary teeth ${ }^{[6]}$. They are more common in second and third decades of life and are rare in the first decade $^{[4,5]}$. In recent review the substantial majority of $D C$ in children involve the mandibular second premolar and the mandibular second molar, followed by the maxillary canines and rarely the mandibular incisors ${ }^{[7]}$. Dentigerous cysts are treated by enucleation or marsupialization/decompression methods. Dentigerous cysts have a good prognosis ${ }^{[8]}$. 
The main objective of this paper is to describe the clinical, radiographical, and histopathological findings of a case of DC in a child patient with mixed dentition involving unerupted right mandibular canine (tooth \#43).

\section{Case Presentation}

An 11-year-old Saudi boy was referred to a private specialist orthodontist regarding delayed eruption of teeth \#43 and \#33. The patient's medical and family history was insignificant. The patient reported a slight discomfort on teeth \#42 and \#41 associated with biting and chewing. Intra-oral examination revealed that the patient presented a mixed dentition with an eruptive backlog of tooth \#43 (Fig. 1 and 2). Examination of the orthopantomogram (OPG) revealed an impacted tooth \#43 against the roots of teeth \#42 and \#41. There was slight widening around the crown of the tooth \#43 but this was not investigated further. At this stage, there was no sign of DC in the OPG and clinically the decision was made to extract mandibular primary canines and mandibular left first primary molar. Then, lingual arch space maintainer with a distal arm on \#42 was constructed to give a chance to \#43 and \#33 for possible self-correction. The patient was monitored every 6 months.

At the six months review, the symptoms in terms of tenderness upon biting and thermal sensitivity from tooth \#42 increased and the patient started to feel the same symptoms with tooth \#41 as well. At this stage, another OPG revealed a rapid change in the position of tooth \#43 associated with the displacement of the roots of teeth \#41 and \#42 (Fig. 3). A decision was made to take cone beam computed tomography (CBCT) (Siemens 3T Skyra, Siemens Medical Solutions, Erlangen, Germany) to explore the area involving tooth \#43 properly.

The $\mathrm{CBCT}$ revealed an apparent follicular space with respect to unerupted tooth \#43 (Fig. 4). A decision
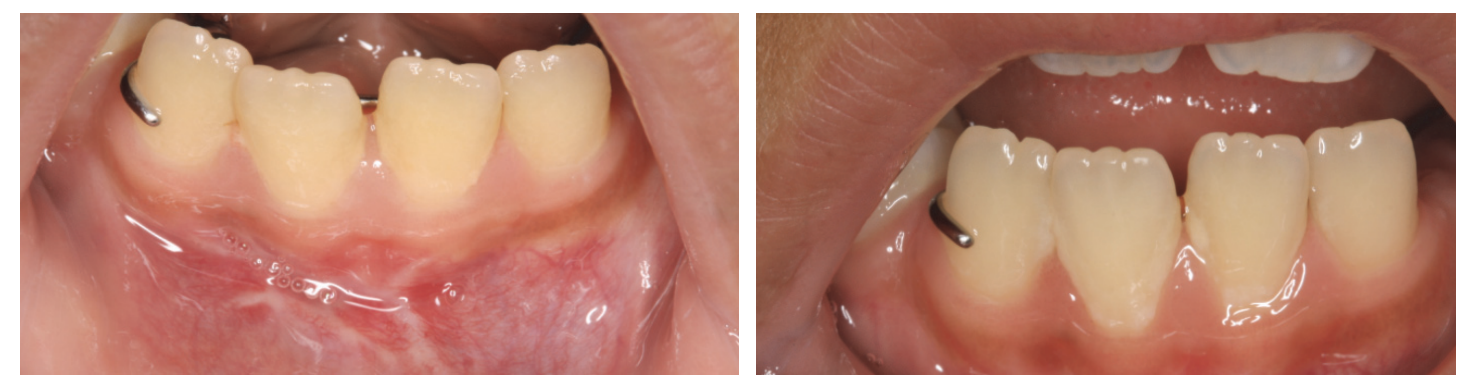

Figure 1. Initial intra-oral photographs.

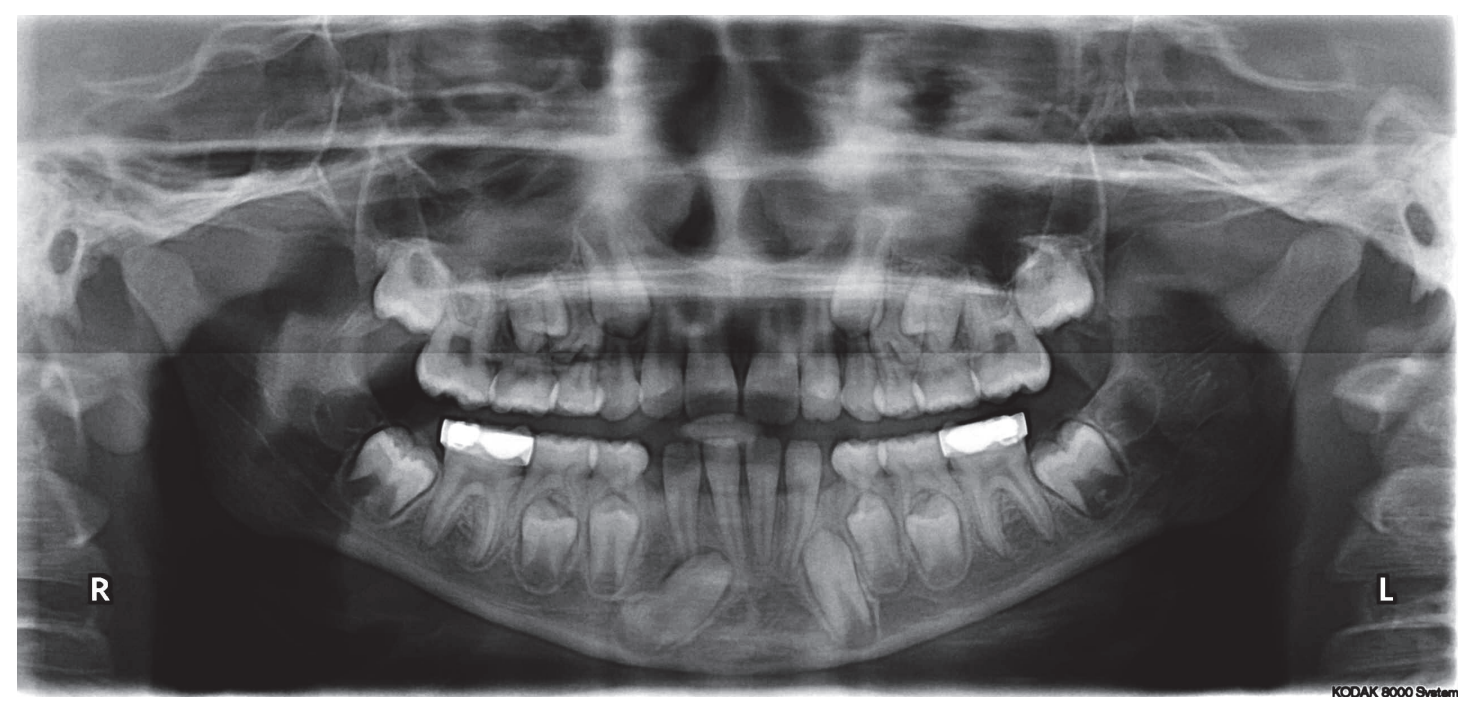

Figure 2. An initial orthopantomogram. 
was made to extract the tooth \#43 with complete enucleation of the lesion and to submit the biopsy for histopathology. The crown of the impacted tooth \#43 was in close contact with the roots of both \#41 and \#42 teeth. A provisional diagnosis of DC was made correlating the clinical and radiographic findings. The patient was referred to specialist periodontist for surgical removal of the DC. Informed consent was obtained from parents for both surgical intervention and publication.

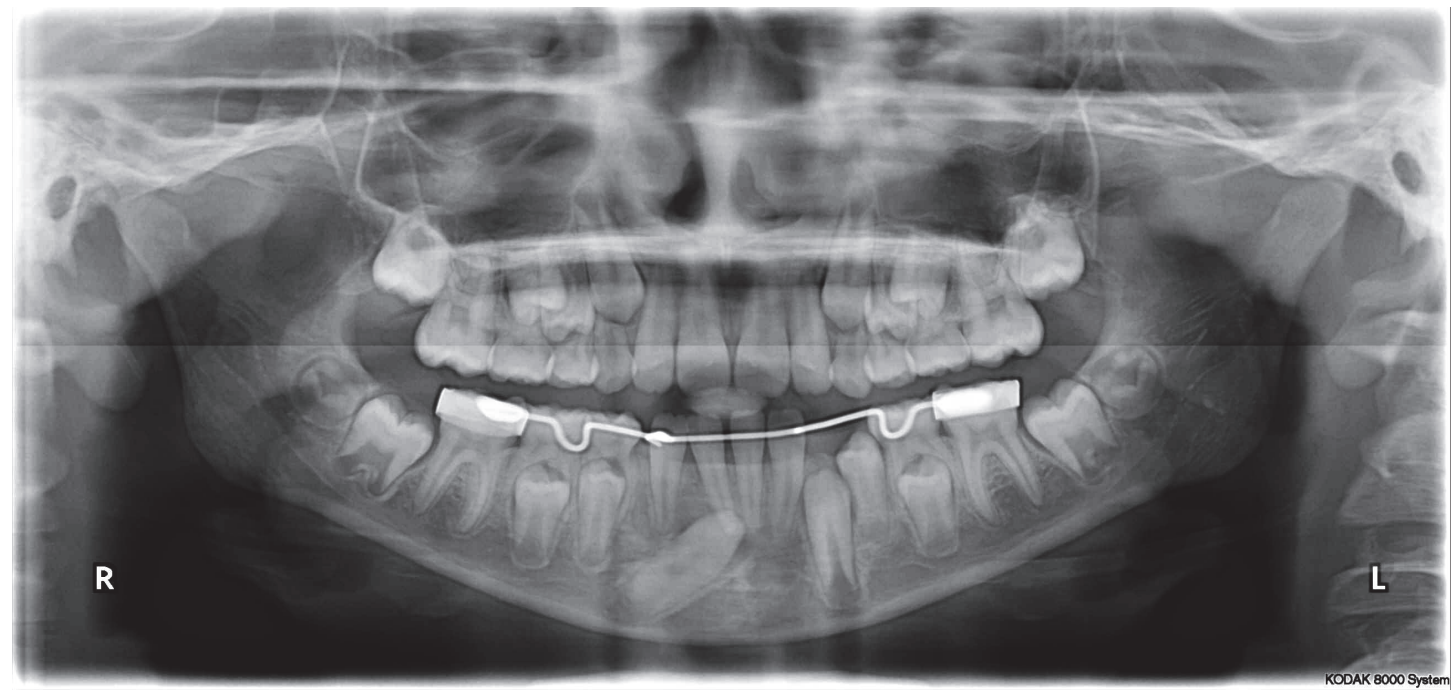

Figure 3. Six months follow-up orthopantomogram.
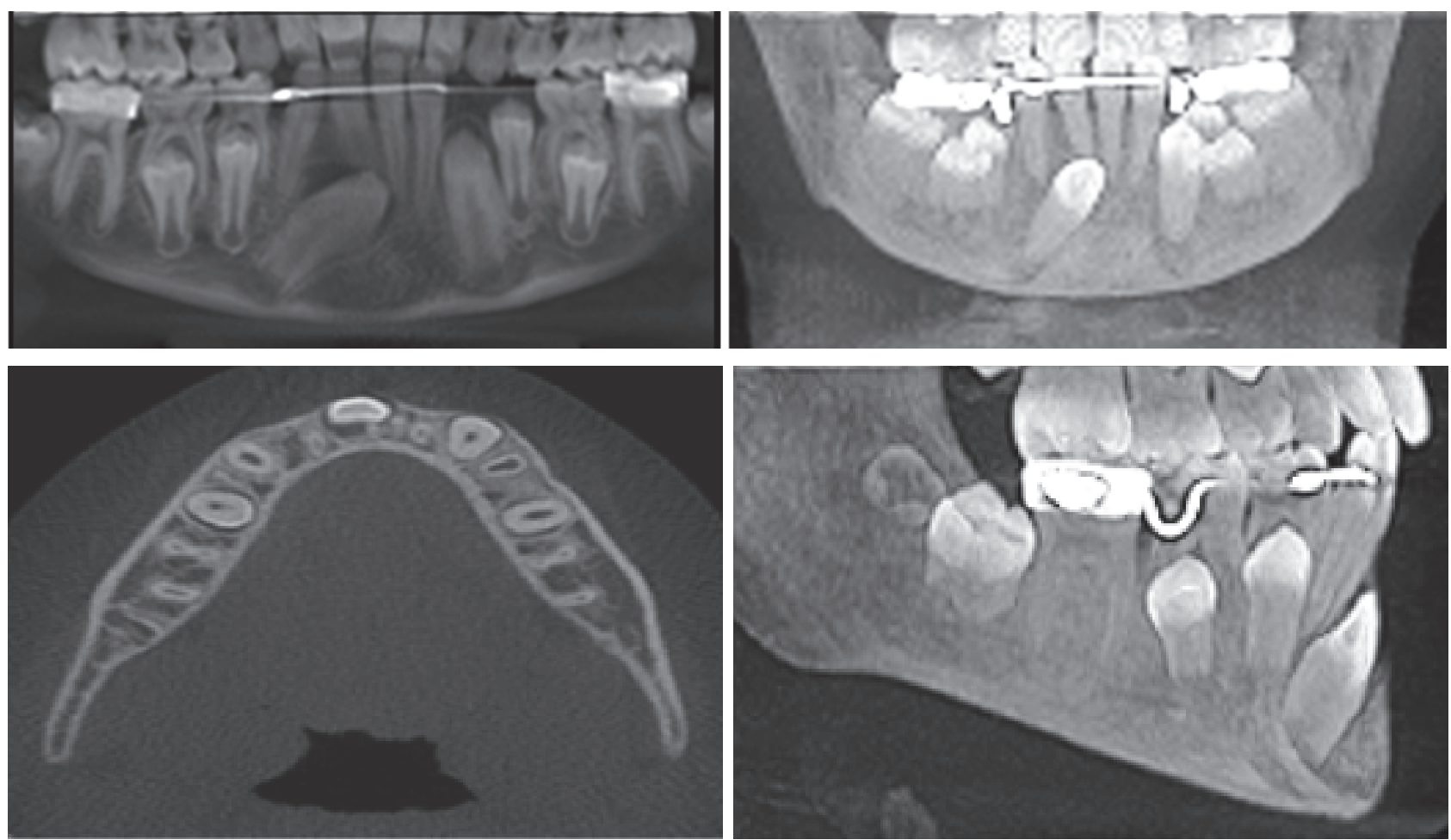

Figure 4. Pre-operative CBCT. 
The surgical procedure planned to be as atraumatic as possible with an emphasis placed on saving the adjacent teeth and the surrounding bone. Enucleation of the cyst was performed under local anesthesia. Small horizontal incision (Swann-Morton Limited, No 3, Sheffield, England) was made extending from the mesial of tooth \#31 to the distal of tooth \#42, incision was made in the keratinized gingival region and avoiding the free gingival margin. The crown of the tooth \#43 was removed followed by the root using means of periotome (Hu-Friedy MFG. Co., Inc., $3232 \mathrm{~N}$, Chicago, IL, USA) and straight elevators (HuFriedy MFG. Co., Inc. EL5SSM, Chicago, IL, USA). The wound was closed using prolene sutures (Ethicon Inc., Johnson \& Johnson, Cornelia, GA, USA) in primary manner. Photographs were taken at 10 days, 4 weeks and 6 months review revealing progressive healing of the soft tissues (Fig. 5). Six months post-operative CBCT revealed optimum bone fill (Fig. 6). Histopathologic analysis of the tissue showed a cyst lined by thin nonkeratinized epithelium. This was supported by unremarkable fibromyxomatous connective tissue. The results were consistent with DC (Fig. 7). The patient was referred again to the orthodontic clinic for the management of delayed eruption of tooth \#33.

\section{Discussion}

Dentigerous cysts are benign odontogenic cysts associated with the crown of unerupted or impacted permanent teeth ${ }^{[9]}$. It can cause cortical plate expansion and result in facial asymmetry ${ }^{[10]}$. Radiographically, a DC appears as a well-defined unilocular radiolucency surrounding the crown of an unerupted tooth ${ }^{[11]}$. Other radiolucent lesions, such as radicular cyst, odontogenic keratocyst, ameloblastoma, and odontoma should be differentially diagnosed with $\mathrm{DC}^{[12]}$. Radiograph alone cannot differentiate the above-mentioned lesions, so a histopathological examination should be performed. Additionally, the epithelial cells lining the lumen of the dentigerous cyst possess an unusual ability to undergo metaplastic transition. Untreated dentigerous cysts rarely develop into an odontogenic tumor or a malignancy like squamous cell carcinoma. Therefore, the early diagnosis and treatment of a dentigerous cyst lesion creates an important opportunity for the prevention of the occurrence of more destructive lesions ${ }^{[13]}$.

Two types of DC are reported in the literature: Developmental and inflammatory types. The
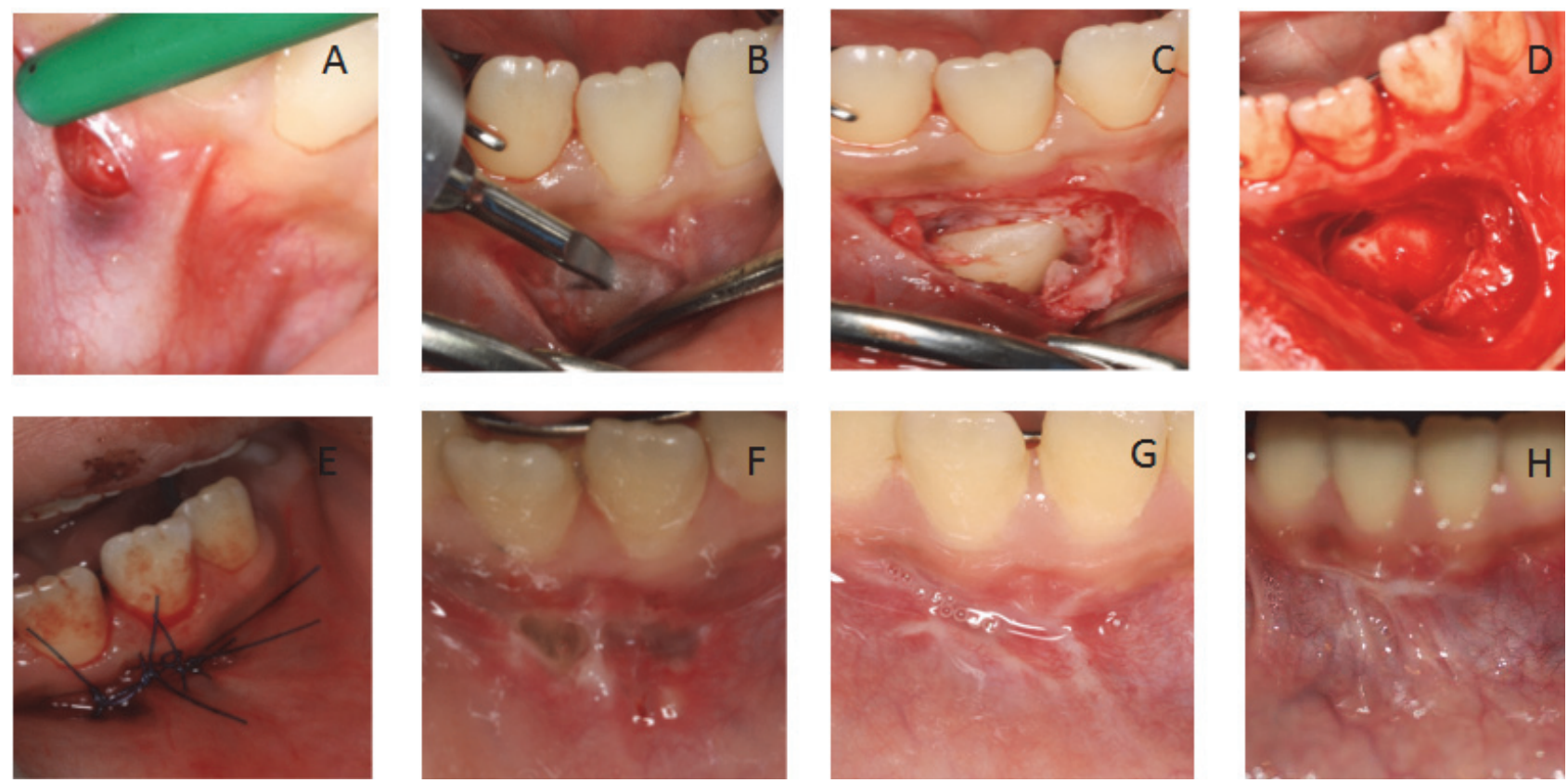

Figure 5. Intra-operative (A, B, C, D, E), post-operative ( $F, G)$ and 6 months review $(H)$ clinical photographs. 

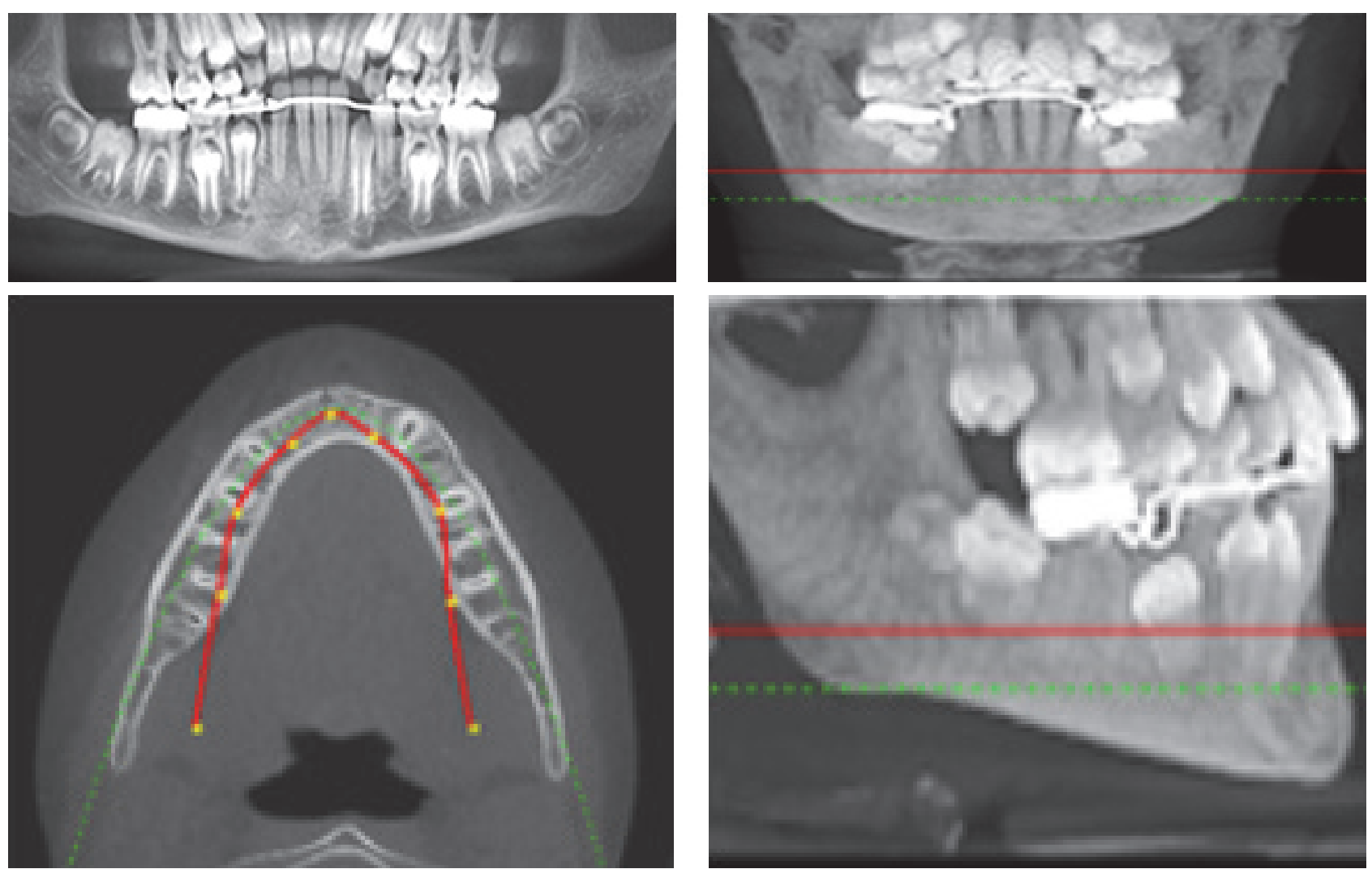

Figure 6. Six months post-operative CBCT.
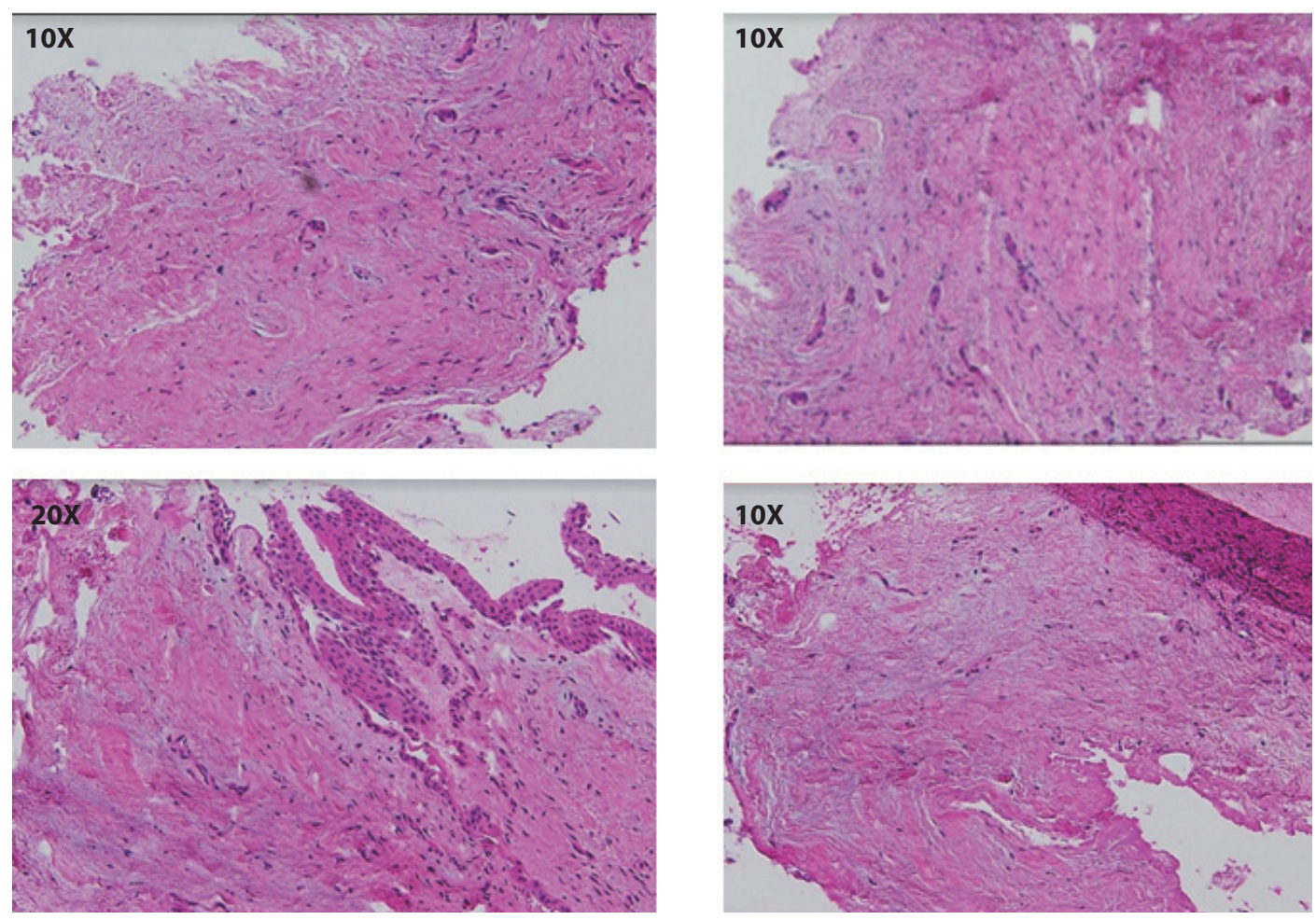

Figure 7. Photomicrographs showing partially ulcerated lining epithelium, which is thin and non-keratinized, covering the cyst wall. 
developmental type of these cysts is the most common type, which surrounds the crown of an unerupted tooth by the fluid accumulation between the layers of the enamel organ ${ }^{[14]}$. This fluid accumulation might be a result of pressure exerted by a potentially erupting tooth on the follicle, which obstructs the venous outflow and induces serum transudation across the capillary wall[15].

Sharp and Helsper ${ }^{[16]}$ has demonstrated that DC is caused by an alteration of the normal development of the tooth germ related to mechanical obstruction or an eruptive deviation.

Dentigerous cysts are usually discovered during routine X-ray examinations or when X-ray is indicated to determine the reason for a failed tooth eruption ${ }^{[17]}$. Orthopantomogram is a low-cost imaging method widely used in routine dentistry; however it produces a two-dimensional image which only allows two dimensions of the lesion to be observed and does not show its relation to adjacent anatomical structures ${ }^{[18]}$. Observation of the third dimension, that is, the buccolingual extension of the lesion, requires additional $\mathrm{X}$-rays taken at 90 degrees to the original view ${ }^{[18]}$. Correct identification of lesions is often impossible in two-dimensional viewing of the image, which may lead to an incorrect selection of treatment plan and finally incorrect performance by the dentist. Cone beam computed tomography offers the advantage of a multiplane image (axial, coronal, and sagittal planes) which gives important information on the presence and extension of bone reabsorption, sclerosis of neighboring bone, cortical expansion, and internal or external calcifications, as well as showing the proximity to other important anatomical structures ${ }^{[19]}$.

In the present case, a CBCT was necessary due to a rapid change in the position of tooth \#43 associated with the displacement of the roots of teeth \#41 and \#42 on OPG. Cone beam computed tomography revealed an apparent follicular space with respect to unerupted tooth \#43. This case report emphasizes the importance of proper radiographic examination of all unerupted teeth using CBCT for better delineation of the extent of the location and its relationship to the adjacent anatomical structures including the permeant teeth.

The factors such as the size and location of the cystic lesion can change the treatment option ${ }^{[20]}$. Various treatment modalities include complete enucleation and marsupialization. The choice of treatment depends on various factors, such as age of the patient, location of the cyst, tooth position in relation to the cyst, and the degree of the axial inclination and root formation ${ }^{[20]}$. If the cyst is associated with a supernumerary tooth, complete enucleation of the cyst along with extraction of the tooth may be the first choice ${ }^{[21]}$.

It is being suggested that marsupialization of the cyst lining is the treatment of choice for DC in children in order to give a chance to the unerupted tooth to erupt, the major disadvantage of marsupialization is that pathologic tissue is left in situ, without a thorough histologic examination ${ }^{[22]}$.

In our case, enucleation with primary closure was the treatment choice as the cyst was small, and was surrounding the unerupted canine and was firmly attached to it. Also, the unerupted canine was displaced to such an extent that it could not be moved to the correct position in the dental arch and there was displacement of the roots of mandibular incisors. All these factors favored enucleation and extraction rather than the marsupialization treatment. This is in agreement with many studies confirming that treatment of DC is usually surgical, which may consist of enucleation and extraction of the teeth embedded in it or affected by it ${ }^{[20-23]}$.

\section{Conclusion}

The diagnosis and early treatment of lesions in children is of great importance, above all in case reports where lesions enclose permanent teeth in order to minimize the associated damage to what is done. A longterm follow-up is important for the diagnosis of the recurrence as well.

We should always study and where possible opt for a conservative attitude that allows for the maintenance of the dentition and treatment of the associated cyst in order to not compromise either the occlusion or the mental state of these patients.

\section{Conflict of Interest}

The authors have no conflict of interest.

\section{Disclosure}

None of the authors received any type of commercial support either in forms of compensation or financial for 
this study. They have no financial interest in any of the products or devices, or drugs mentioned in this article.

\section{Ethical Approval}

Obtained.

\section{References}

[1] Souza LB, Gordón-Núñez MA, Nonaka CFW, Medeiros MC, Torres TF, Emiliano GBG. Odontogenic cysts: demographic profile in a Brazilian population over a 38-year period. Med Oral Patol Oral Bucal 2010; 15: e583-e590.

[2] Shah A, Gill DS, Tredwin C, Naini FB. Diagnosis and management of supernumerary teeth. Dent Update 2008; 35(8): 510-512, 514-516, 519-520.

[3] Ko KS, Dover DG, Jordan RC. Bilateral dentigerous cysts: report of an unusual case and review of literature. J Can Dent Assoc 1999; 65(1): 49-51.

[4] Neville BW, Damm DD, Allen CM, Bonquot JE. Oral and Maxillofacial pathology. 2nd ed. Philadelphia, PA, USA: WB Saunders, 2005. 591-592.

[5] Freitas DQ, Tempest LM, Sicoli E, Lopes-Neto FC. Bilateral dentigerous cyst: Review of literature and report of unusual case. Dento Maxillofac Radiol 2006; 35: 64-68.

[6] Kumar S, Charantimath S, Byakodi R, Shwetha RS. Non syndromic bilateral mandibular dentigerous cysts in a 7 year old child- report of a rare case. Int J Contemp Dent 2011; 2: 101-104.

[7] AlTuwirqi A, Khzam N. What do we know about dentigerous cysts in children: a review of literature. J Res Med Dent Sci 2017; 5(2): 67-79.

[8] Kumar R, Singh RK, Pandey RK, Mohammad S, Ram H. Inflammatory dentigerous cyst in a 10-year-old child. Natl J Maxillofac Surg 2012; 3(1): 80-83.

[9] Berti Sde A, Pompermayer AB, Couto Souza PH, Tanaka OM, Westphalen VP, Westphalen FH. Spontaneous eruption of a canine after marsupialization of an infected dentigerous cyst. Am J Orthod Dentofac Orthop 2010; 137(5): 690-693.

[10] Ertas U, Yavuz MS. Interesting eruption of 4 teeth associated with a large dentigerous cyst in mandible by only marsupialization. J Oral Maxillofac Surg 2003; 61(6): 728-730.

[11] Benn A, Altini M. Dentigerous cysts of inflammatory origin. A clinicopathologic study. Oral Surg Oral Med Oral Pathol Oral Radiol Endod 1996; 81(2): 203-209.

[12] Cury SE, Cury MD, Pontes FS, Pontes HA, Rodini C, PintoDdos S Jr. Bilateral dentigerous cyst in a nonsyndromic patient: case report and literature review. J Dent Child (Chic) 2009; 76(1): 92-96.

[13] Bharath KP, Revathy V, Poornima S, Subba Reddy W. Dentigerous cyst in an uncommon site: A rare entity. J
Indian Soc Pedod Prev Dent 2011; 29 (Suppl2): S99-103.

[14] Tilakraj TN, Kiran NK, Mukunda KS, Rao S. Non syndromic unilateral dentigerous cyst in a 4-year-old child: a rare case report. Contemp Clin Dent 2011; 2(4): 398-401.

[15] Harris M, Toller P. The pathogenesis of dental cysts. Br Med Bull 1975; 31(2): 159-163.

[16] Sharp GS, Helsper JT. Radiolucent spaces in the jaws. Am J Surg 1969; 118(5): 712-725.

[17] Regezi JA, Sciubba JJ, Pogrel MA. Atlas of Oral and Maxillofacial Pathology. Philadelphia, Pa, USA: WB Saunders, 2000. 66.

[18] Ahmad M, Jenny J, Downie M. Application of cone beam computed tomography in oral and maxillofacial surgery. Australian Dent J 2012; 57 (Suppl1): S82-94.

[19] McCrea S. Adjacent dentigerous cysts with the ectopic displacement of a third mandibular molar and supernumerary (forth) molar: a rare occurrence. Oral Surg Oral Med Oral Pathol Oral Radiol Endod 2009; 107(6): e1520.

[20] Demiriz L, Misir AF, Gorur Dl. Dentigerous cyst in a young child. Eur J Dent 2015; 9(4): 599-602.

[21] Sharma D, Garg S, Singh G, Swami S. Trauma-induced dentigerous cyst involving an inverted impacted mesiodens: case report. Dent Traumatol 2010; 26(3): 289291.

[22] Takagi S, Koyama S. Guided eruption of an impacted second premolar associated with a dentigerous cyst in the maxillary sinus of a 6 yr old child. J Oral Maxillofac Surg 1998; 56(2): 237-239.

[23] Aguiló L, Gandía JL. Dentigerous cyst of mandibular second premolar in a five-year-old girl, related to a nonvital primary molar removed one year earlier: a case report. J Clin Pediatr Dent 1998; 22(2): 155-158. 


\title{
الانتظار أو التذخل: لتكيس سني مرتبط بالناب السفلي الدائم
}

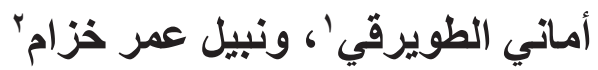

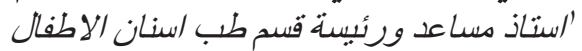 \\ كلية طب الأسنان

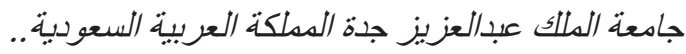

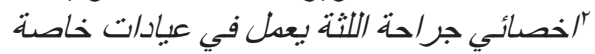 \\ بيرث /ستر البيان
}

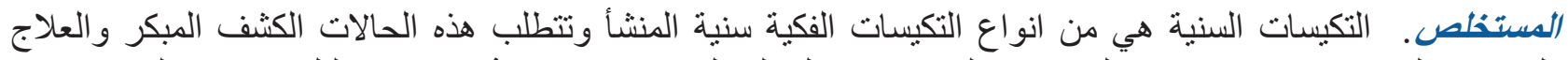

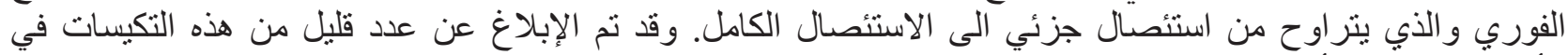

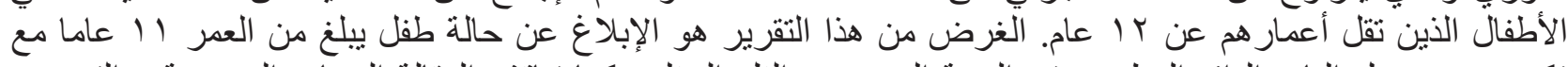

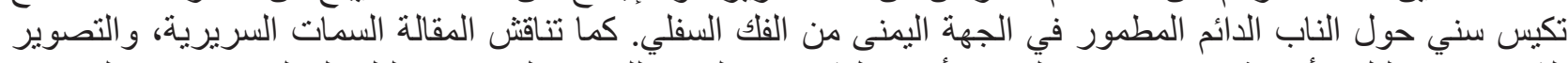

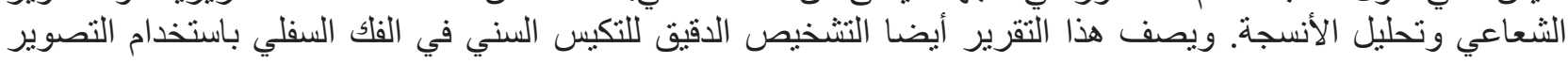

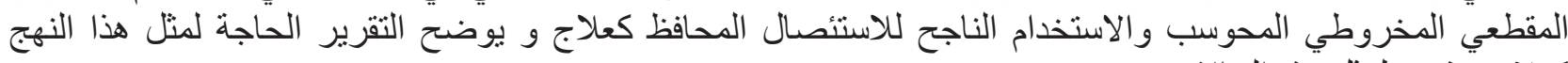
كعلاج جذري لمثل هذه الحالات. 